\title{
Enterocyte proliferation and intracellular bacteria in animals
}

\author{
S McOrist, C J Gebhart, G H K Lawson
}

Considerable proliferation of enterocytes, forming adenomatous growths within the intestinal mucosa, is a consistent feature of a number of enteric conditions in animals, now referred to under the general heading of proliferative enteropathy. These were originally described in pigs as adenomas of the ileum and colon $^{1}$ and this condition was found to have a worldwide occurrence. ${ }^{2}$ Similar conditions were subsequently described in a number of other animal species, again under the general heading of proliferative enteropathy or enteritis. The degree, however, of mucosal proliferation, corresponding to a description of hyperplasia, through adenoma to a more carcinomatous form, varies between species. Occasional reports of the condition in the fox, ${ }^{3}$ horse, ${ }^{4}$ and guinea pig ${ }^{5}$ describe a hyperplastic condition of the mucosa whereas hamsters ${ }^{6} 7$ develop adenomatous lesions similar to the pig, and the rat $^{8}$ and ferret ${ }^{9}$ can develop an apparently carcinomatous condition with true metastases to local lymph nodes. Study of the disease was revolutionised in 1974 by the discovery that these lesions in pigs had the consistent presence of intracellular bacteria lying free in the cytoplasm of proliferating enterocytes. ${ }^{10}$ These bacteria were not detected in normal animals or in unaffected portions of the intestine. The disease is infectious and is transmitted by oral exposure of animals to diseased mucosa.

The wide variety and occurrence of these lesions in animals prompted comparisons with some ileocolic conditions in humans, such as Crohn's disease. Comparative studies of the lesions, however, and serological testing, ${ }^{11} 12$ including a study by Crohn himself, ${ }^{13}$ showed that proliferative enteropathy in animals had no clear counterpart in humans. There may be some mechanistic comparisons with the food sensitive enteropathies, including coeliac disease, in which primary crypt cell hyperplasia is thought to play a part in pathogenesis. ${ }^{11}$ This still leaves open the question of how an enteric bacterium, albeit one living inside enterocytes, can change host cell metabolism to induce a hyperplastic or even carcinomatous state. Previous exploration of this phenomenon was hampered by a lack of knowledge of the bacterium involved. Many early studies considered the bacteria morphologically similar to vibrio or campylobacters and several campylobacter species were proposed as candidates for the bacteria involved. ${ }^{2}$ Recent work shows that the intracellular bacteria are a new genus of obligate intracellular bacteria, living within enterocytes. This report describes recent advances in the taxonomic status of the bacteria and its association with disease pathogenesis in animals, focusing on how this can aid an understanding of enterocyte proliferation.

\section{Intracellular bacteria}

The intracellular bacteria in proliferative enteropathy in animals have been closely studied in the pig and hamster species, in which the disease is common and widespread. Clinical diagnosis of infection and disease is, however, difficult ${ }^{2}$ and the disease might be recognised more widely if diagnostic tools became available. Morphologically, the bacteria have a wavy trilaminar cell wall and granular protoplasm typical of Gram negative bacteria. ${ }^{10}$ They tend to be curved bacilli, sometimes sigmoid, with ends tapering to a rounded extremity. ${ }^{14}$ They divide by transverse septation. Healthy and dividing bacteria have only been seen within mammalian enterocytes. Some degenerate forms have been seen in mucosal macrophages. ${ }^{2}$ The healthy bacterial forms seem similar morphologically in all variations of host species and pathology. Antigenic studies of these bacteria in several host species including pigs, hamsters, ferrets, rats, guinea pigs, fox, horse, and deer show that they also share outer membrane antigens. ${ }^{15} 16$ These antigens are distinct from those of other curved bacteria found in the gut. ${ }^{17}$ Preliminary and more definitive studies of the DNA of these bacteria show that they form a distinct new genus within the delta group of Proteobacteria. ${ }^{18} 19$ Porcine strains of the bacteria have been designated an ileal symbiont intracellularis. ${ }^{19}$ Their relation to strains from other hosts is not yet known, but results of preliminary antigenic and DNA analyses show that they are almost identical.

These DNA studies showed a 91\% homology of the 16S rDNA portion of the genome to Desulfovibrio desulfuricans. ${ }^{19}$ These are one of the predominant sulphate reducing bacteria in the colon and can use molecular $\mathrm{H}_{2}$ as an electron donor. ${ }^{20}$ This may point to some distant evolutionary or functional relation, or both, to the intracellular bacteria. 
The method of entry of the bacteria into host enterocytes is probably by parasite directed endocytosis, with attachment of the bacteria to the brush border surface, formation of an entry vacuole, and early release free into the cytoplasm, where multiplication and division occurs. ${ }^{21}$ Some of these biological features are similar to that of some chlamydia and rickettsia species. For example, $R$ tsutsugamushi lie freely in the cytoplasm of infected fibroblasts. ${ }^{22}$ Intracellular bacteria are characterised by a wide variety of entry and survival mechanisms. ${ }^{23}$ These mechanisms are not, however, indicative of any particular evolutionary relation between bacteria that have similar modes of entry and survival. ${ }^{23}$ There does seem to be some common ground in the general scheme of regulation of attachment, entry, and survival genes and their products. Bacteria in the gut lumen must possess the ability to recognise features of their external environment, such as temperature, osmolarity or anaerobiosis, to regulate the expression of genes active in attachment and entry into enterocytes. Recent reviews ${ }^{24} 25$ provide many examples, such as the detection of anaerobiosis postulated for the expression of the invasion phenotype of Salmonella typhimurium for entry into mammalian cells. After entry into cells, intracellular bacteria may detect environmental calcium or other signals ${ }^{2425}$ regulating the action of genes necessary for intracellular survival.

In some instances, we have found that the bacteria within enterocytes lie closely associated with mitochondria and rough endoplasmic reticulum. Similar findings in cells infected with other intracellular bacteria have led to the suggestion that these intracellular bacteria may derive some benefit from triphosphates produced by the host cells, ${ }^{26}$ possibly by incorporation of these into bacterial respiration.

\section{Enterocyte proliferation}

The remarkable presence of intracellular bacteria within enterocytes is made even more remarkable by the clear temporal and causative relation between the appearance of these bacteria and the development of proliferation of the enterocytes leading to gross hyperplasia, adenoma or carcinoma. Many early experiments in which pigs were inoculated with bacteria derived directly from homogenates of affected mucosa ${ }^{7427}$ and later experiments using ileal symbiont intracellularis grown in cultured intestinal epithelial cells ${ }^{28}$ as the inoculum clearly showed that the bacteria had entered host enterocytes by five to seven days after dosing. Hyperplasia of infected mucosal epithelium was then evident 10 to 14 days after dosing, with gross lesions visible in some cases 21 days after dosing. Histological examination of lesions points to mitosis and piling up of immature enterocytes in defined, but long, branching crypt structures. Some of those cells may die, appearing as apoptotic bodies. In recovering lesions, goblet cells reappear in affected crypts and normal mucosal crypts regenerate. Despite the detection by others of enteric viruses and Chlamydia $s p$ in some experimental inocula or animals, 2729 it is probable that ileal symbiont intracellularis can act as a sole initiating agent of proliferative enteropathy. ${ }^{2830}$ There seems to be some host specificity in the ability to produce lesions. Although organisms derived from lesions in the pig can produce lesions in orally dosed hamsters, ${ }^{31}$ these tend not to be as florid as lesions produced by hamster derived isolates. Immunological and DNA analyses, including 16S rDNA gene sequence data, have shown that the organisms within pig and hamster enterocytes are almost identical. ${ }^{16}$

Therefore the apparent differences in abnormal reactions upon oral transmission of inocula to a separate host species may only reflect a reduced ability of inoculated bacteria to compete with the differing gut flora of another host species and effect colonisation. Dosing of primates has not been reported. The exact relation of intracellular bacteria to the carcinomatous lesions in rats has not been clearly established, but further experiments may clarify this.

Experiments and clinical data show that animals are most susceptible to infection just after weaning from their mother. ${ }^{32}$ This may reflect a greater proportion of permissive crypt epithelial cells within the intestine or a more protective intraluminal environment for bacterial colonisation, or both. Recent experiments in germ free pigs, recently weaned pigs with a normal gut flora, and pigs with a defined gut flora of four non-pathogenic bacteria supported the concept that the degree of gut maturity and luminal conditions attained at weaning greatly enhances colonisation and disease due to ileal symbiont intracellularis. ${ }^{28} 30$

The evidence suggests that enterocyte proliferation in animals can be caused directly by a transmissible agent, identified as a delta group Proteobacteria closely related to the sulphate reducing bacteria. Current knowledge of proliferative enteropathy is insufficient to suggest how a bacterium can influence enterocytes to start comparatively uncontrolled growth. Any proposed mechanism would have to take into account the dynamics of crypt epithelial cell production by monoclonal stem cells, with subsequent proliferation and vertical elevation into adjacent villi, as outlined elsewhere. ${ }^{32}$ Some possible mechanisms, however, can be postulated. Firstly, the bacterium could possess an intrinsic mitogenic factor, which is either expressed constitutively or upon intracellular entry. Such a mitogen has been postulated to be a virulence factor of Bartonella bacilliformis, ${ }^{33}$ the Gram negative intracellular bacterium that is the cause of endothelial cell proliferation in the dermal verruga of Bartonellosis. ${ }^{34}$ Secondly, the bacteria could share receptor binding capacity with natural ligands such as tumour growth factor $\alpha$ or other growth factors, although this would not explain why the organism requires an intracellular phase. A transmissible colonic hyperplasia of mice caused by a Citrobacter

\section{ภ}

.


freundii like organism 3536 apparently occurs without any need for intracellular entry, occurring after attachment of the bacteria to the brush border. This organism has recently been shown to contain an attaching and effacing locus homologous to the eae gene of enteropathogenic Escherichia coli. ${ }^{37}$ This raises the possibility that a group of gut bacteria possess at least two mechanisms to change epithelial cell growth, one which acts extracellularly and one which acts intracellularly. Patients with colon adenomas can have a greater predominance of anaerobes in their colonic flora than control subjects. ${ }^{38} 39$ Whether this is merely a by product of colonic stasis or is indicative of a functional relation between colonic bacteria and enterocyte proliferation is not clear. Further investigation of the type and taxonomic status of colonic flora in adenoma patients may prove of interest. This is not to imply that there is an increased risk of colon cancer from contact with the gut flora of pigs or other animals; no such risk has been shown clearly in relevant occupational categories in epidemiological studies. ${ }^{40}$ Many other mechanisms have been suggested whereby gut bacteria can participate in local cancer formation. For example, production of carcinogenic bile acid metabolites by anaerobic bacteria may occur in the formation of some colon cancers in humans. ${ }^{39}$

\section{Other host responses}

The immune response to bacterial infection in proliferative enteropathy is characterised by a weak humoral and cellular response. ${ }^{4142}$ Specific IgA and IgM are detected in the serum samples of severe clinical cases in pigs, but carrier or subclinical states could not be detected serologically. ${ }^{41}$ Examination of affected intestines shows appreciable accumulation of IgA in the cytoplasm of affected cells, but little evidence of $T$ cell infiltration, particularly in early lesions. ${ }^{42}$ The initial lesions of mucosal hyperplasia seem to be remarkably free of lymphocytic infiltration and proliferation of enterocytes in adenomatous crypt formation predominates. ${ }^{110}$ These can extend into underlying Peyer's patches and even to mesenteric lymph nodes, particularly in the rat $^{8}$ and ferret, ${ }^{9}$ but also occasionally in the pig. ${ }^{43}$ Only in later lesions, probably of several weeks' duration, is an infiltrate of cytotoxic and activated (CD8+, CD25+) lymphocytes evident in the mucosa. ${ }^{42}$ Secondary infection by necrotising bacteria, causing a diffuse necrotic enteritis on top of the proliferative enteropathy is comparatively common in pigs and hamsters. ${ }^{2}{ }^{7}$ It has been suggested that this weak and delayed immune response is at least partly caused by the ability of bacteria residing within the crypt enterocytes of pigs to escape immune surveillance to some degree. ${ }^{42}$ Somewhat similar disturbances of normal immune response patterns may occur in patients with inflammatory bowel disease, wherein the local recruitment of cytotoxic $T$ cells is delayed, possibly because of a defect in normal enterocyte activity. ${ }^{44} 45$ The accumulation of $\operatorname{IgA}$ in affected enterocytes possibly results from the disruption of their normal activity by the presence of intracellular bacteria, or from the immaturity of the affected cells.

In conclusion, the occurrence of a common disease in animals, in which the presence of intracellular bacteria of the delta group of Proteobacteria clearly triggers massive proliferation of enterocytes, offers food for thought for gastroenterologists. Can bacteria in the gut interact with host cell membrane receptors that affect growth? Can some bacteria produce mitogenic factors acting locally on the bowel? The elucidation of the mechanisms underlying host cell proliferation induced by these bacteria will be the next goal.

1 Beister HE, Schwarte LH. Intestinal adenoma in swine. $A m$ f Pathol 1931; 7: 175-85.

2 Rowland AC, Lawson GHK. Porcine proliferative enteropathies. In: Leman AD, Straw BE, Mengeling WL, D'Allaire S, Taylor DJ, eds. Diseases of swine. $7 \mathrm{th}$ ed. Ames: Iowa State University Press, 1992: 560-9.

3 Eriksen K, Landsverk J. Interstinal adenomatosis in the blue fox. Nordic Veterinaria Medica 1985; 37: 254-5.

4 Duhamel GE, Wheeldon EB. Intestinal adenomatosis in a foal. Vet Pathol 1982; 19: 447-50.

5 Elwell MR, Chapman AL, Frenkel JK. Duodenal hyperplasia in a guinea pig. Vet Pathol 1980; 17: 136-9.

6 Frisk CS, Wagner JE. Experimental hamster enteritis: an electron microscopic study. Am $\mathcal{F}$ Vet Res 1977; 44: 1861-8.

7 Jacoby RO. Transmissible ileal hyperplasia of hamsters. I. Histogenesis and immunocytochemistry. Am $\mathcal{F}$ Pathol 1978; 91: 433-50.

8 Vandenberghe J, Verheyen A, Lauwers S, et al. Spontaneous adenocarcinoma of the ascending colon in Wistar rats: the intracytoplasmic presence of a Campylobacter-like bacterium. F Comp Pathol 1985; 95: 45-55.

9 Fox JG, Murphy JC, Otto G, et al. Proliferative colitis in ferrets: epithelial dysplasia and translocation. Vet Pathol 1989; 26: 515-7.

10 Rowland AC, Lawson GHK. Intestinal adenomatosis in the pig: immunofluorescent and electron microscopic studies. pig: immunofluorescent and 2 .

11 MacDonald TT. Epithelial proliferation in response to gastro-intestinal inflammation. Ann NYAcad Sci 1992; 664: 202-9.

12 Mayberry JF, Rhodes J, Heatley RV. Infections which cause ileocolic disease in animals: are they relevant to Crohn's disease? Gastroenterology 1980; 78: 1080-4.

13 Crohn BB, Turner DA. Porcine ileitis. Gastroenterology 1952; 20: 350-1.

14 McOrist S, Lawson GHK, Rowland AC, et al. Early lesions of proliferative enteritis in pigs and hamsters. Vet Pathol 1989; 26: $260-4$.

15 Lawson GHK, Rowland AC, MacIntyre N. Demonstration of a new intracellular antigen in porcine intestinal adenomatosis and hamster proliferative ileitis. Vet Microbiol matosis and ham

16 McOrist S, Boid R, Lawson GHK, et al. Monoclonal antibodies to intracellular Campylobacter-like organisms of bodies to intracellular Campylobacter-like organisms of porcine

17 McOrist S, Boid R, Lawson GHK. Antigenic analysis of Campylobacter species and an intracellular Campylobacter-like organism associated with porcine proliferative enteropathies. Infect Immun 1989; 57: 957-62.

18 McOrist S, Lawson GHK, Roy DJ. DNA analysis of intracellular Campylobacter-like organisms associated with porcine proliferative enteropathies: novel organism proposed. FEMS Microbiol Lett 1990; 69: 189-94.

19 Gebhart CJ, Barns SM, McOrist S, et al. Ileal symbiont intracellularis, an obligate intracellular bacterium of porcine intestines showing a relationship to Desulfovibrio porcine intestines showing a relationship to

20 Gibson GR, MacFarlane GT, Cummings JH. Sulphate reducing bacteria and hydrogen metabolism in the human large intestine. Gut 1993; 34: 437-9.

21 Johnson EA, Jacoby RO. Transmissible ileal hyperplasia of hamsters. II. Ultrastructure. Am $\mathcal{f}$ Pathol 1978; 91 451-68.

22 Hanson B. Factors influencing Rickettsia tsutsumagush infection. of cultured cells. Am $\mathcal{F}$ Trop Med Hyg 1987; 36: 621-30.

23 Moulder JW. Comparative biology of intracellular parasitism. Microbiol Rev 1985; 49: 298-337.

24 Mekalonos JJ. Environmental signals controlling expression of virulence determinants in bacteria. $\mathcal{F}$ Bacteriol 1992; 174: $1-7$.

25 Wick MJ, Madara JL, Fields BN, et al. Molecular cross-talk between epithelial cells and pathogenic microorganisms. Cell 1991; 67: 651-9.

26 Horowitz MA. Formation of a novel phagosome by the Legionnaire's disease bacterium (Legionella pneumophila) in human monocytes. $\mathcal{F}$ Exp Med 1983; 158: 1319-31. 
27 Mapother ME, Joens LA, Glock RD. Experimental reproduction of porcine proliferative enteritis. Vet Rec 1987; 121: 533-6.

28 McOrist S, Jasni S, Mackie RA, et al. Reproduction of porcine proliferative enteropathy with pure culture of ileal symbiont intracellularis. Infect Immun 1993; 61: 4286-92.

29 Fox JG, Stills HR, Paster BJ, et al. Antigenic specificity and morphologic characteristics of Chlamydia trachomatis strain SFPD isolated from hamsters with proliferative ileitis. Lab Anim Sci 1993; 43: 405-10.

30 McOrist S, Mackie RA, Neef N, et al. Synergism between gut flora and ileal symbiont intracellularis in porcine proliferative enteropathy. Vet Rec 1994; 134: 331-2.

31 McOrist S, Lawson GHK. Possible relationship of proliferative enteritis in pigs and hamsters. Vet Microbiol 1987; 15: 293-302.

32 Schmidt GH, Wilkinson MT, Ponder BAJ. Cell migration pathway in the intestinal epithelium: an in situ marker system using mouse aggregation chimeras. Cell 1985; 40: 425-9.

33 Garcia FU, Wojta J, Broadley KN, et al. Bartonella bacilliformis stimulates endothelial cells in vitro and is angiogenic in vivo. Am f Pathol 1990; 136: 1125-35.

34 Arias-Stella J, Leiberman PH, Erlandson RA, et al. Histology, immunochemistry and ultrastructure of the veruga in Carrion disease. Am $\mathcal{F}$ Surg Pathol 1986; 10: 595-610.

35 Barthold SW, Asbaldiston GW, Jones AM. Dietary bacterial and host genetic interactions in the pathogenesis of ial and host genetic interactions in the pathogenesis of 1977; 27: 838-45.

36 Barthold SW, Coleman GL, Jacoby RO, et al. Transmissible murine colonic hyperplasia. Vet Pathol 1978; 15: 223-36.
37 Schauer DB, Falkow S. Attaching and effacing locus of a Citrobacter freundii biotype that causes transmissible Citrobacter freundii biotype that causes transmissible murine colonic hyperplasia. Infect Immun 1993; 61:

38 Mastromasino AJ, Reddy BS, Wynder EL. Profiles of anaerobic microflora of large bowel cancer patients and patients with non-hereditary large bowel polyps. Cancer Res 1978; 38: 4458-62.

39 Van der Werf SDJ, Nagengast FM, Van Berge GPH. Intracolonic environment and the presence of colonic adenomas in man. Gut 1983; 24: 876-80.

40 Brownson RC, Zahm SH, Chang JC, et al. Occupational risk of colon cancer. $A m \mathcal{F}$ Epidemiol 1989; 130: 675-87.

41 Lawson GHK, McOrist S, Rowland AC, et al. Serological diagnosis of the porcine proliferative enteropathies: implications for aetiology and epidemiology. Vet Rec 1988; 122: cations

42 McOrist S, MacIntyre N, Stokes CR, et al. Immunocytological responses in porcine proliferative enteropathies. Infect Immun 1992; 60: 4184-91.

43 Roberts L, Rowland AC, Lawson GHK. Porcine intestinal adenomatosis: epithelial dysplasia and infiltration. Gut 1980; 21 : 1035-40.

44 Mayer L, Eisenhardt D. Lack of induction of suppressor T cells by intestinal epithelial cells from patients with inflammatory bowel disease 7 Clin Invest 1990; 86: 1255-60.

45 Mayer L, Eisenhardt D, Salomon P, et al. Expression of class II molecules on intestinal epithelial cells in humans. Differences between normal and inflammatory bowel disease. Gastroenterology 1991; 100: 3-12. 